
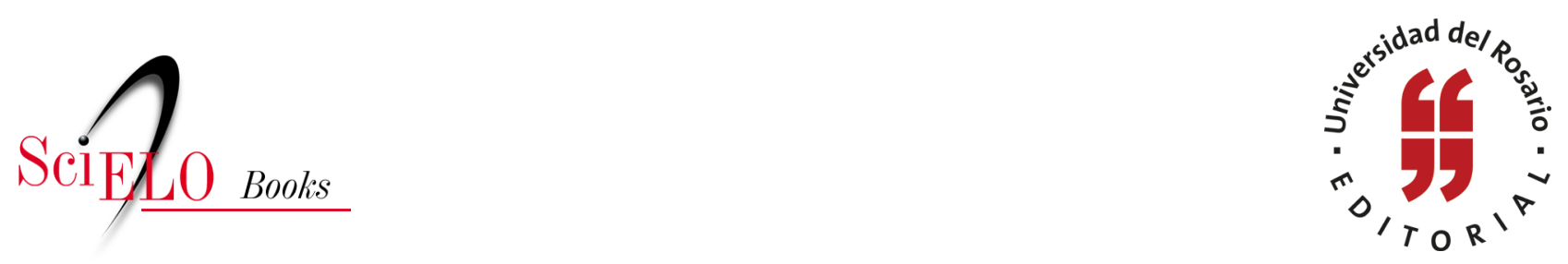

\title{
5. La facultad a prevención
}

\author{
Andrés Gómez Rey \\ Gloria Amparo Rodríguez \\ Iván Vargas Chaves
}

\section{SciELO Books / SciELO Livros / SciELO Libros}

GÓMEZ REY, A., AMPARO RODÍGUES, G., and VARGAS CHAVES, I. La facultad a prevención. In: AMPARO RODRÍGUEZ, G., and VARGAS CHAVES, I., ed. Perspectivas de responsabilidad por daños ambientales en Colombia [online]. Bogotá: Editorial Universidad del Rosario, 2015, pp. 143-162. Textos de Jurisprudencia collection. ISBN: 978-958-738-644-8.

https://doi.org/10.7476/9789587386448.0006.

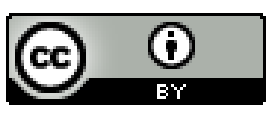

All the contents of this work, except where otherwise noted, is licensed under a Creative Commons Attribution 4.0 International license.

Todo o conteúdo deste trabalho, exceto quando houver ressalva, é publicado sob a licença Creative Commons Atribição 4.0.

Todo el contenido de esta obra, excepto donde se indique lo contrario, está bajo licencia de la licencia $\underline{\text { Creative }}$ Commons Reconocimento 4.0 . 


\title{
5. La facultad a prevención
}

\author{
Andrés Gómez Rey* \\ Gloria Amparo Rodríguez** \\ Iván Vargas Chaves ${ }^{* * * *}$
}

\section{Introducción}

A partir de la expedición de la Ley 1333 de 2009, fue establecido en Colombia el régimen sancionatorio administrativo ambiental, ${ }^{1}$ el cual ha generado amplios debates por su particular estructura y contenido. Entre lo más llamativo encontramos: a) comprende un régimen de responsabilidad personal;

* Abogado de la Universidad de La Sabana; especialista en Derecho Ambiental de la Universidad del Rosario; magíster en Derecho Administrativo de la Universidad del Rosario. Profesor de cátedra de pregrado y posgrado de diversas instituciones, entre ellas la Universidad del Rosario, la Universidad Icesi y la Universidad de La Salle; ha sido asesor de entidades como el Ministerio de Ambiente y Desarrollo Sostenible, la Defensoría del Pueblo, la Superintendencia de Servicios Públicos Domiciliarios y algunas Corporaciones Autónomas Regionales. De igual manera, acompaña a empresas privadas en temas ambientales, especialmente en procedimientos sancionatorios. Cuenta con diversas publicaciones sobre derecho ambiental y servicios públicos domiciliarios. Correo electrónico: agomezrey@icloud.com

** Abogada; especialista en Derecho Ambiental, Negociación, Conciliación y Arbitraje, y Derecho Médico y Sanitario de la Universidad del Rosario; magíster en Medio Ambiente y Desarrollo con énfasis en Gestión Ambiental de la Universidad Nacional de Colombia; y doctora en Sociología Jurídica e Instituciones Políticas de la Universidad Externado de Colombia. Actualmente, se desempeña como profesora principal de carrera de la Facultad de Jurisprudencia de la Universidad del Rosario, donde además es directora de la Especialización y de la Línea de Investigación en Derecho Ambiental. Cuenta con diferentes publicaciones sobre temas ambientales y étnicos, y ha sido editora académica de otras obras. Correo electrónico: gloria.rodriguez@urosario.edu.co

** Abogado de la Universidad del Rosario; magíster en Derecho de la Universidad de Génova (Italia). Actualmente, es investigador en formación doctoral en la Universidad de Barcelona y profesor adscrito de Derecho Ambiental en la Universidad Nacional Autónoma de México. Correo electrónico: ivargas@outlook.com

${ }^{1}$ Sin olvidar lógicamente sus antecedentes, como el artículo 339 del Decreto-Ley 2811 de 1974, el Decreto 1594 de 1984 (se debe precisar que todos los decretos reglamentarios hoy han sido recogidos por la norma única del sector ambiente: Decreto 1076 de 2015), el artículo 85 de la Ley 99 de 1993, modificados y derogados por la Ley 1333 de 2009. 
b) establece dos formas de convertirse en infractor, en palabras de Rodríguez, Gómez y Monroy (2012, p. 237): por violación de las normas² de contenido ambiental o por configurarse los elementos de la responsabilidad civil extracontractual, determinados en el artículo 2341 del Código Civil; ${ }^{3}$ c) se trata de un compendio normativo que refleja un régimen de responsabilidad subjetiva por cuanto contempla como elementos: el hecho, la culpa o el dolo, el nexo causal y el daño. Lo cual llama la atención puesto que los ordenamientos jurídicos de otros países van encaminados a la configuración de la responsabilidad objetiva en los temas ambientales; d) aunque la responsabilidad y el procedimiento como es natural debe ser permeado por los principios constitucionales y legales, ${ }^{4}$ como el debido proceso (presunción de inocencia y otros), trae consigo la presunción de la culpa o el dolo y la inversión de la carga de la prueba, lo cual además fue avalado por nuestra Corte Constitucional (Sents. C-595/10, C-1007/10 y C-742/10); e) posee en la doctrina críticas que llevan a pensar que, tanto por la forma en la cual fue estructurada la ley como por el comportamiento de sus operadores jurídicos, se tratará de un régimen que comprende un sistema que presume todos los elementos de la responsabilidad (Rodríguez, Gómez y Monroy, 2012, p. 246). ${ }^{5}$

${ }^{2}$ Entiéndase por normas aquellas emanadas del poder legislativo, así como actos administrativos.

${ }^{3} \mathrm{Si}$ bien es cierto que se entiende como 'agente' o sujeto pasivo de la acción sancionatoria ambiental configurar los elementos de la responsabilidad civil extracontractual, esto no implica de ninguna manera una remisión a las reglas y demás contenido de esta forma o tipo de responsabilidad. Así pues, la solidaridad y otras figuras no contemplan expresa remisión.

${ }^{4}$ En especial, los contenidos en a) los artículos 29,209 y otros de nuestra Constitución Política; b) los comprendidos en el artículo 1º de la Ley 99 de 1993; c) aquellos del artículo 3o de la Ley 1437 de 2011 o Código de Procedimiento Administrativo y de lo Contencioso Administrativo; y d) los generales de la actuación y función administrativa y del derecho punitivo. Tales como la prohibición de la analogía, el non bis in idem, la doble instancia, la no retroactividad de la ley, el debido proceso (presunción de inocencia, principio de legalidad, nulla poena sine lege, derecho de contradicción, no dilación injustificada en los trámites administrativos) y la buena fe.

${ }^{5}$ Para mayor comprensión, ya que se trata de un tema sumamente teórico, se recomienda consultar la fuente citada. En este sentido, no pretenden los autores detenerse en la presente idea, sino simplemente mostrar parte de lo que existe en la doctrina como novedades del régimen sancionatorio ambiental colombiano. Sin embargo, diremos: a) para explicarlo en términos simples: la autoridad ambiental, al conocer la presunta infracción, señala a una persona que considere relacionada con esta — sin mayor sustento probatorio- Con ello, tiene la autoridad vinculado al procedimiento: el daño (producto de la infracción), el sujeto que ella eligió y nexo causal. Quedando faltando la culpa y el dolo, que la ley los presume. Por tal razón, todos los elementos quedan presuntos. b) Para explicarlo desde el punto de vista teórico: la autoridad ambiental conoce el daño y señala a una persona que considera relacionada con la 
La Ley 1333 de 2009, además de las anteriores particularidades, contempla en su artículo $2^{\circ}$ la llamada facultad a prevención, figura que llama la atención por sus novedades, que estudiaremos y analizaremos en el presente texto. El artículo $2^{\circ}$ de la mencionada norma establece:

Artículo $2^{\circ}$. Facultad a prevención. El Ministerio de Ambiente, Vivienda y Desarrollo Territorial; la Unidad Administrativa Especial del Sistema de Parques Nacionales Naturales; las Corporaciones Autónomas Regionales y las de Desarrollo Sostenible; las unidades ambientales urbanas de los grandes centros urbanos a que se refiere el artículo 66 de la Ley 99 de 1993; los establecimientos públicos a los que hace alusión el artículo 13 de la Ley 768 de 2002; la Armada Nacional; así como los departamentos, municipios y distritos, quedan investidos a prevención de la respectiva autoridad en materia sancionatoria ambiental. En consecuencia, estas autoridades están habilitadas para imponer y ejecutar las medidas preventivas y sancionatorias consagradas en esta ley y que sean aplicables, según el caso, sin perjuicio de las competencias legales de otras autoridades. Parágrafo. En todo caso las sanciones solamente podrán ser impuestas por la autoridad ambiental competente para otorgar la respectiva licencia ambiental, permiso, concesión y demás autorizaciones ambientales e instrumentos de manejo y control ambiental, previo agotamiento del procedimiento sancionatorio. Para el efecto anterior, la autoridad que haya impuesto la medida preventiva deberá dar traslado de las actuaciones a la autoridad ambiental competente, dentro de los cinco (5) días hábiles siguientes a la imposición de la misma.

\footnotetext{
infracción, presume entonces el sujeto, el nexo y el daño. Como la culpa y el dolo, la ley los presume, todos los elementos son presuntos (es una responsabilidad que presume todos sus elementos). En términos jurídico-teóricos: cuando la culpa es presunta, el hecho real causante del daño es desconocido (es decir, la culpa desconocida se considera la causante del daño); por tal razón, el nexo causal corre la misma suerte so pena de ser inoperante. Pero lo anterior genera un peligro para los involucrados, ya que el presunto responsable puede llegar a ser cualquiera, así se encuentre alejado de la cadena de responsabilidad. "En otras palabras, como en la realidad se conoce una violación o una afectación que prende las alarmas de la autoridad ambiental, se vincula a cualquier sujeto del cual se presume su culpa y por ende el nexo causal entre los primeros y se configuran de manera presunta todos los elementos de la responsabilidad" (Rodríguez, Gómez y Monroy, 2012, p. 248).
} 
Aunque de su mera lectura no pareciera tener mayores inconvenientes, desde la óptica del derecho administrativo sí, ya que fue diseñada para quebrantar parte de la antigua teoría general del acto administrativo. Entonces, encontramos que vía ley ha comenzado el derecho ambiental a construir una estructura por fuera del derecho administrativo. Siendo entonces interesante detenernos en dicha institución a través del presente escrito.

Para lograr analizar y estudiar la facultad a prevención, hemos planteado como estructura del documento: primero (cuestiones generales), un aparte sobre los elementos de juicio necesarios para el estudio de la 'facultad a prevención' desde el punto de vista del derecho administrativo, donde se hará referencia al concepto de acto administrativo; los elementos de existencia, en especial, los atinentes al órgano y competencia; y las consecuencias de la inobservancia de los citados elementos, para mostrar cómo está construido el derecho administrativo de manera general. Segundo (cuestiones específicas), un aparte sobre el análisis de la figura 'facultad a prevención', con el fin de mostrar las razones por las cuales su creación fue más allá de las posibilidades y reglas de dicho público; para así terminar con la recopilación in genere de lo observado.

El aspecto metodológico recaerá de manera principal en el análisis dogmático del derecho (sistemas descriptivos), a través del cual se realizará una recopilación bibliográfica especializada sobre la materia, incluyendo, lógicamente, la consulta de las fuentes del derecho: ley, jurisprudencia y doctrina.

\subsection{Parte general. Conceptos del derecho administrativo necesarios para el análisis de la facultad a prevención}

A continuación, estudiaremos brevemente las generalidades del acto administrativo y de la teoría general del acto administrativo necesarias para entender lo particular y especial de la figura llamara facultad a prevención. A manera de introito, traeremos algunas de las definiciones de acto administrativo, para contextualizar el objeto al cual nos referiremos:

$\mathrm{E}$ l acto administrativo ${ }^{6}$ es entendido como fundamento e institución principal del derecho administrativo por ser el instrumento básico de manifestación y ejercicio de la actividad de la administración, así como de comu-

\footnotetext{
${ }^{6}$ Siguiendo en esta definición la tesis de maestría de uno de los autores: Gómez Rey (2012b).
} 
nicación con las personas en la nación. Vidal Perdomo (1994, p. 132) propone que es el producto jurídico de la función administrativa; Santofimio (1998, p. 125) afirma que el acto administrativo ha adquirido en los sistemas jurídicos modernos, especialmente en aquellos ceñidos por los principios del Estado de derecho, connotaciones de columna vertebral del derecho administrativo. Lo anterior no solo desde el punto de vista del ejercicio de la función administrativa, sino también del régimen de garantías que se desprende de su existencia.

E1 Consejo de Estado (sentencia del 30 de abril de 1998) entiende por acto administrativo "la expresión de voluntad de una autoridad o de un particular en ejercicio de funciones administrativas, que modifique el ordenamiento jurídico, es decir, que por sí misma cree, extinga o modifique una situación jurídica", destacando como componentes de su esencia la voluntad, el organismo que lo expide y los efectos jurídicos llamados a producir (sentencia del 9 de noviembre de 1998). Por último, diremos que Penagos (2008, p. 20) lo define como una "decisión unilateral de naturaleza administrativa, de cualquier órgano del Estado, o de los particulares autorizados por la ley, con la finalidad de crear, modificar o extinguir una relación jurídica”.

Siguiendo a Berrocal (2001, p. 121), el acto administrativo es toda declaración o decisión unilateral que en ejercicio de la función administrativa esté llamada a producir efectos jurídicos.

Con lo dicho, nótese que esas características de las decisiones estatales comprenden una serie de elementos para su existencia, validez y eficacia, los cuales, en caso de ser incumplidos, tendrán un 'castigo', o padecerán de 'vicios'o 'patologías'. Por tal razón, a continuación, veremos aquellos de especial importancia para el estudio de la facultad a prevención contenida en la Ley 1333 de 2009.

\subsubsection{Del órgano y la competencia}

Toda decisión que sea adoptada por parte de las entidades del Estado debe cumplir con los elementos o condiciones propuestas en la teoría general del acto administrativo (Penagos, 2008, p. 20), a saber: a) de existencia: órgano, competencia y contenido; b) de validez: voluntad, forma y procedimiento; y c) de eficacia u oponibilidad: publicación, notificación o comunicación. No obstante, para efectos de estudiar la 'facultad a prevención', haremos énfasis únicamente en los de la existencia. 
El primer elemento de la existencia del acto administrativo es conocido como el órgano, órgano competente o sujeto activo, que, según Penagos (2001, p. 281), es aquel que tiene la capacidad jurídica para proferir actos administrativos, "[...] es decir, que el acto administrativo, debe emanar de un órgano con capacidad jurídica para ejercer la función administrativa, manifestada en actos administrativos [...]".

Entonces, quien tome decisiones a través de actos administrativos deberá estar facultado por el ordenamiento jurídico para hacerlo teniendo en cuenta que "ninguna autoridad del Estado podrá ejercer funciones distintas de las que le atribuyen la Constitución y la ley" (c.P., art. 121), lo cual se conoce como principio de legalidad.

Así,las posibilidades de actuación de todas las entidades del Estado (de todas sus ramas o funciones del poder público, incluidos los particulares en ejercicio de la función administrativa) poseen como límite los preceptos que la ley establece, de los cuales no deben ni pueden escapar. Piénsese entonces que, si las autoridades que componen el Sistema Nacional Ambiental, ${ }^{7}$ encargadas de la protección, preservación y cuidado (in genere) de los recursos naturales de conformidad con lo dispuesto en la Ley 99 de 1993, emiten una decisión tendiente a cesar los efectos civiles de un contrato matrimonial, estaría pues este acto incumpliendo el elemento objeto de estudio.

El órgano o sujeto activo de la competencia, como lo explica Santofimio (1998, p. 140), es, por regla general, el depositario de la competencia necesaria para crear el acto administrativo, esto es, el órgano del Estado revestido de funciones administrativas para adoptar decisiones de manera unilateral

${ }^{7}$ a) El Ministerio de Ambiente y Desarrollo Sostenible, antes Ministerio de Ambiente, Vivienda y Desarrollo Territorial, fue creado con la Ley 99 de 1993 como rector y encargado de formular la política ambiental colombiana. Se constituye como la cabeza visible del organigrama estatal.b) Las Corporaciones Autónomas Regionales y las de Desarrollo Sostenible, quienes son autoridad ambiental de carácter regional, llamadas a la protección y vigilancia de los recursos naturales renovables.c) Los grandes centros urbanos que, de conformidad con lo dispuesto en el artículo 66 de la Ley 99 de 1993, poseen las mismas funciones de las CAR, en el área urbana de los municipios con una población mayor o igual a un millón de habitantes. d) Los institutos de investigación y el subsistema de investigación ambiental, llamados a generar tendencias técnicas sobre la materia. Sobre estos hay que indicar que, aunque poseen funciones similares a las CAR, no se conoce permiso ambiental por ellos otorgados. Entre ellos encontramos el Instituto de Investigación de Recursos Biológicos Alexander von Humboldt, el Instituto Amazónico de Investigaciones Científicas Sinchi y el Instituto de Investigaciones Ambientales del Pacífico John von Neumann. e) Las unidades ambientales urbanas y la Unidad Administrativa Especial del Sistema de Parques Nacionales Naturales. 
tendientes a crear, modificar o extinguir en relaciones en el mundo jurídico, el cual será quien, bajo las reglas de la teoría de los actos administrativos unilaterales, contemple la competencia para actuar.

A su vez, la competencia (aquello que el ordenamiento jurídico asigna al órgano o sujeto activo), de acuerdo con Rodríguez (2001,p. 247), es la facultad o poder jurídico que tiene una autoridad para ejercer determinada función. Es expresa, ${ }^{8}$ irrenunciable ${ }^{9}$ e improrrogable,${ }^{10}$ y debe ser ejercida directamente por quien posea la capacidad legal.

Adicionalmente, plantea Rodríguez (2001) que la competencia posee tres elementos:
[...] la competencia ratione materiae. Se refiere al elemento material de la competencia, es decir, al objeto de ella. Ese objeto se traduce en las diferentes funciones que una autoridad puede ejercer legalmente [...]. La competencia ratione loci. Es la competencia territorial, o sea, el territorio dentro del cual la autoridad puede ejercer legalmente sus funciones [...]. La competencia ratione temporis. Es la competencia temporal. Se refiere al tiempo durante el cual la autoridad puede ejercer legalmente sus funciones.

Por último, el mismo autor cuenta que "[...] se reconoce doctrinariamente que la capacidad entrándose en la teoría del acto administrativo se traduce en términos de competencia. En este sentido, será capaz la autoridad que tiene competencia para el ejercicio de un asunto [...]", fusionando pues en una sola condición la competencia y el órgano.

\subsubsection{Del incumplimiento del órgano y la competencia}

Sobre la competencia dice Rodríguez (2001, p. 247) que esta facultad es dada por la ley y es un requisito de orden público, es decir que es de estricto cumplimiento, de manera que, si no existe, el acto nace, pero viciado de ilegalidad. A

\footnotetext{
${ }^{8}$ Ya que debe estar clara y plenamente consagrada en el ordenamiento jurídico.

${ }^{9}$ Por cuanto el funcionario debe ejercer las obligaciones establecidas en los manuales de funciones o similares, sin que pueda abstraerse de ellas.

${ }^{10}$ Puesto que no depende de la voluntad de la personas, sino de la necesidad de cumplir con los fines propios del Estado.
} 
su vez, y según García (2008, p. 119), expone que, en presencia del incumplimiento de los requisitos de órgano y competencia, la decisión estatal “[...] es el acto no nacido, no venido a la vida jurídica por faltarle un elemento sustancial para ello [...]".

Encontrando con ello dos de las posiciones jurídicas predominantes sobre la materia: la inexistencia del acto administrativo y la presencia de vicios graves que generan su nulidad derivada de la inobservancia de los elementos órgano y competencia. ${ }^{11}$

La inexistencia, plantea el Consejo de Estado (sentencia del 6 de diciembre de 2012) citando a Vedel Georges:
[...] se trata de una de las cuestiones más delicadas e inciertas del contencioso-administrativo. La noción de inexistencia parece haber sido tomada del derecho civil; corresponde a la idea de que ciertos vicios son de tal forma graves que afectan no solamente a la validez del acto jurídico, sino incluso a su propia 'existencia' [...]. En dere- cho administrativo la utilización de la noción de inexistencia en la jurisprudencia ha sido bastante cambiante según las épocas [...].

Entonces, hace referencia a que, aunque la decisión está presente en el mundo o la realidad (digamos, se encuentra un papel cuyo contenido tuviese apariencia de acto administrativo), por incumplimiento de los elementos de existencia (órgano, competencia y contenido), se debe entender que esta nunca nació a la vida jurídica y, por tal razón, no genera efectos sobre los coasociados (derecho u obligaciones).

Debemos reconocer que se trata de una posición complicada al ser de difícil aplicación en la vida práctica. Recordando el hipotético ejemplo anteriormente expuesto, en el cual una autoridad del sina emite una decisión para dejar sin efectos civiles un contrato matrimonial, piénsese que el particular simplemente hace caso omiso de esta por considerarla inexistente, lo cual trasladaría el examen de existencia del acto administrativo al sujeto recibo de sus efectos o a la interpretación de su operador jurídico.

${ }^{11}$ Entre ellas: usurpación de funciones o por inexistencia de estas en el ordenamiento jurídico. 
Para comprender la cuestión, citemos a Penagos (2008, p. 341):

[...] Cuando hablamos de inexistencia del acto administrativo, nos referimos a una categoría que aparentemente es acto. En cambio, cuando se dice que el acto está viciado de nulidad, se indica una decisión que existe en el mundo jurídico, pero afectada de un vicio ${ }^{12}$ [...] Lo que importa diferenciar entre el acto viciado y el inexistente es la gravedad de la irregularidad.

No puede existir, por ejemplo, un acuerdo municipal sin Concejo que lo expida, por inexistencia del órgano, así como tampoco puede existir un acto sin contenido.

La inexistencia es la nada jurídica, por ejemplo, es imposible que alguien que no es funcionario, ni esté autorizado por la ley, pueda proferir un acto administrativo [...] Un acto administrativo o una operación administrativa no pierden su carácter administrativo aunque sean irregulares [...] sin embargo, en ciertos casos la irregularidad es tan grave o tan evidente que el acto no es atribuible, ni siquiera en virtud de un vínculo dudoso [...] se dice entonces que hay 'vías de hecho'.

Con lo dicho, no debe proponerse la inexistencia de actos administrativos físicos que sean irregulares, sino la presencia de patologías que vician su vida y estabilidad jurídica. Sin embargo, cuando la decisión sea exorbitantemente irregular (como ordenar la tortura pública de un ciudadano) se tratará de una vía de hecho.

A esta conclusión llega el Consejo de Estado (sentencia del 6 de diciembre de 2012) al afirmar que "en su tratado M. de Labaudére, da una excelente puntualización de la cuestión, que resumimos como sigue: a) caso del acto absolutamente inexistente. Es el acto que no ha sido efectuado jamás o que ha sido adoptado por un individuo que no tiene la calidad de autoridad o de agente público [...] La inexistencia absoluta tiene como consecuencias que nadie puede tener en cuenta tal acto, que no es susceptible de producir ningún efecto [...]”.

En suma, el incumplimiento del 'órgano'y la 'competencia' como elementos de existencia del acto administrativo no genera que la decisión deba conside-

\footnotetext{
${ }^{12}$ Bien sea por inconstitucionalidad o por las causales generales comprendidas en la acción de nulidad descrita en el artículo 137 de la Ley 1437 de 2011.
} 
rarse inexistente, sino que posee vicios en su formación y, por tal razón, deberá ser controvertida ante los jueces de la república. Con lo dicho, entonces, cuando una autoridad asuma la competencia de otra, las decisiones por ella adoptadas presentarán vicios por tal razón.

Santofimio (1998, p. 350) nos cuenta que los vicios producto de la usurpación de funciones, definida por él como la “[...] intromisión grosera de un órgano u autoridad respecto de las competencias de las otras [...]", los cuales están siempre cercanos a los vicios por usurpación de autoridad o desviación de poder, en donde se asaltan temporalmente las competencias de un órgano por otro o por alguien sin la investidura para emitir los actos, serán decisiones que deben ser demandadas por cuanto no respetan lo dispuesto en el ordenamiento jurídico.

\subsection{Parte especial. De la facultad a prevención}

De la lectura de la definición de la facultad a prevención que contempla la Ley 1333 de 2009 en su artículo 20 (ya citada en la introducción) ${ }^{13}$ y de lo dicho en el aparte anterior, salta a la vista que dicha figura fue construida por fuera de la teoría general del acto administrativo, ya que está llamada a permitir el incumplimiento del elemento 'órgano' del acto administrativo. Sin embargo, aunque la reflexión propuesta no requiere mayor demostración, veamos algunas acotaciones o características de la figura de manera particular.

\footnotetext{
${ }^{13}$ Recordémosla: "Artículo 2o. Facultad a prevención. E1 Ministerio de Ambiente, Vivienda y Desarrollo Territorial; la Unidad Administrativa Especial del Sistema de Parques Nacionales Naturales; las Corporaciones Autónomas Regionales y las de Desarrollo Sostenible; las unidades ambientales urbanas de los grandes centros urbanos a que se refiere el artículo 66 de la Ley 99 de 1993; los establecimientos públicos a los que hace alusión el artículo 13 de la Ley 768 de 2002; la Armada Nacional; así como los departamentos, municipios y distritos, quedan investidos a prevención de la respectiva autoridad en materia sancionatoria ambiental. En consecuencia, estas autoridades están habilitadas para imponer y ejecutar las medidas preventivas y sancionatorias consagradas en esta ley y que sean aplicables, según el caso, sin perjuicio de las competencias legales de otras autoridades. Parágrafo. En todo caso las sanciones solamente podrán ser impuestas por la autoridad ambiental competente para otorgar la respectiva licencia ambiental, permiso, concesión y demás autorizaciones ambientales e instrumentos de manejo y control ambiental, previo agotamiento del procedimiento sancionatorio. Para el efecto anterior, la autoridad que haya impuesto la medida preventiva deberá dar traslado de las actuaciones a la autoridad ambiental competente, dentro de los cinco (5) días hábiles siguientes a la imposición de la misma”.
} 


\subsection{1. Únicamente podrá ser utilizada por algunas de las entidades del Estado. Sujeto activo de la facultad a prevención}

La Ley 1333 de 2009, que comprende como sujeto activo a aquel que detenta la posibilidad de adelantar procedimientos sancionatorios administrativos contra particulares, recae sobre las autoridades ambientales que tienen dentro de sus funciones el otorgamiento de permisos, concesiones, asociaciones, autorizaciones y licencias ambientales. Por tal razón, Rodríguez, Gómez y Monroy (2012, p. 236) expresan: "Parece prudente comprender, sin embargo, que la ley no asignó competencias sancionatorias a las entidades antes mencionadas de forma directa, por el contrario, indicó que quienes tuvieran facultades para expedir permisos, licencias y autorizaciones serán los sujetos facultados para realizar los procedimientos sancionatorios". ${ }^{14}$

Empero, la facultad a prevención posee diferentes entidades que las podrán utilizar. Veamos: reza la norma que solo podrán ejecutar las acciones relacionadas con la facultad a prevención:

a) El Ministerio de Ambiente, Vivienda y Desarrollo Territorial. En cuanto a esta descripción, debe advertirse que, a partir de la expedición de la Ley 1444 de 2011, se reordenó la institucionalidad ambiental, destacándose la creación de la Autoridad Nacional de Licencias Ambientales (ANLA) a través del Decreto-Ley 3573 de 2011 como una unidad administrativa especial, con autonomía administrativa y financiera, sin personería jurídica, adscrita al Ministerio de Ambiente y Desarrollo Sostenible, encargada de la vigilancia, inspección, seguimiento y control de los proyectos, obras o actividades sujetos a licenciamiento ambiental. Dicha autoridad cuenta entre sus funciones (numerales 1, 2 y 7 del artículo 3º del Decreto-Ley 3573 de 2011) otorgar o negar las licencias, permisos y trámites ambientales de competencia del Ministerio de Ambiente y Desarrollo Sostenible, de conformidad con la ley y los reglamentos; realizar el seguimiento de las licencias, permisos y trámites ambientales; y adelantar y culminar el procedimiento de investigación, preventivo y sancionatorio en materia ambiental, de acuerdo con lo dispuesto en la Ley 1333 de 2009, sobre aquellas actividades que por

${ }^{14}$ No obstante, en los artículos 5º y 31 de la Ley 99 de 1993, y 2o del Decreto-Ley 3570 de 2011, se establecieron competencias expresas. 
competencia haya otorgado licencia, permiso o trámite ambiental, o impuesto planes de manejo ambiental.

Por tal razón, cuando la Ley 1333 de 2009 se refiere al Ministerio de Ambiente y Desarrollo Sostenible en materia permisiva debe entenderse que se está haciendo referencia a la ANLA a través de las funciones establecidas en el Decreto-Ley 3573 de 2011, salvo que se trate de acciones relacionadas con la Convención sobre el Comercio Internacional de Especies Amenazadas de Fauna y Flora Silvestres (Cites), sustracciones de reservas forestales y acceso a recursos genéticos, donde el Ministerio aún conserva la facultad sancionatoria.

b) La Unidad Administrativa Especial del Sistema de Parques Nacionales Naturales, que en el Decreto-Ley 216 de 2003 contempló que cuenta con la administración y manejo de las áreas del Sistema de Parques Nacionales y le atribuyó funciones policivas y sancionatorias.

c) Las Corporaciones Autónomas Regionales y las de Desarrollo Sostenible, que, de conformidad con lo dispuesto en el artículo 31 de la Ley 99 de 1993, comprenden facultades permisivas al ser la máxima autoridad ambiental en su jurisdicción y, por tal razón, poseen la competencia sancionatoria.

d) Las unidades ambientales urbanas de los grandes centros urbanos a que se refiere el artículo 66 de la Ley 99 de 1993. Es decir, serán los municipios, distritos o áreas metropolitanas cuya población urbana fuere igual o superior a un millón de habitantes quienes ejercerán dentro del perímetro urbano las mismas funciones atribuidas a las Corporaciones Autónomas Regionales, en lo que fuere aplicable al medio ambiente urbano.

e) Los establecimientos públicos a los que hace alusión el artículo 13 de la Ley 768 de 2002. Es decir, los distritos de Cartagena, Santa Marta y Barranquilla, que ejercerán, dentro del perímetro urbano de la cabecera distrital, las mismas funciones atribuidas a las Corporaciones Autónomas Regionales en lo que fuere aplicable al medio ambiente urbano, en los mismos términos del artículo 66 de la Ley 99 de 1993. 
f) La Armada Nacional. Siendo la entidad que más llama la atención, ya que, aunque no se encuentra como una entidad (o autoridad) ambiental, tiene la posibilidad de utilizar la figura.

Sobre el particular dos cuestiones son especiales o sui generis: la primera hace referencia a que la Ley 1333 de 2009 adjudicó la facultad sancionatoria llamada a adelantar los procedimientos del ius puniendi estatal únicamente a aquellas entidades que tienen la posibilidad de entregar, estudiar, analizar o negar los permisos, autorizaciones, asociaciones, concesiones o licencias ambientales. ${ }^{15}$ En otras palabras, tendrán las facultades de control aquellos que tengan la facultad ambiental de vigilancia, inspección y seguimiento. Por tal razón, encontrar que existen entidades del Estado que, aunque no puedan otorgar autorizaciones ambientales, puedan usar la figura objeto de estudio es sumamente inconveniente, puesto que no poseen la experticia o el conocimiento de lo que pueda llegar a considerarse una 'infracción desde el punto de vista ambiental'.

La segunda hace referencia a que, si se incluyó a la Armada Nacional, que tiene como misión contribuir a la defensa de la nación a través del empleo efectivo de un poder naval flexible en los espacios marítimo, fluvial y terrestre bajo su responsabilidad, con el propósito de cumplir la función constitucional y participar en el desarrollo del poder marítimo y la protección de los intereses de los colombianos, quien no posee competencias ambientales de vigilancia, seguimiento e inspección, por qué se dejó por fuera al resto de instituciones que hacen parte de nuestras fuerzas militares, como la Policía Nacional, el Ejército Nacional y la Fuerza Aérea Colombiana.

\footnotetext{
${ }^{15}$ Lo anterior sin desconocer que, conforme al artículo 5 de la Ley 1333 de 2009, no toda infracción ambiental es una consecuencia del incumplimiento o ausencia de una licencia, permiso autorización, concesión o asociación ambiental. Existen múltiples infracciones ambientales que no son el resultado del incumplimiento o ausencia de estas, sino, como contempla la ley, por generar un daño en sede de los elementos de la responsabilidad civil extracontractual o violentar una norma de contenido ambiental. No obstante, la competencia para adelantar los procedimientos ambientales la poseen aquellas entidades con facultades permisivas en el interior del Sistema Nacional Ambiental.
} 


\title{
g) Los departamentos, ${ }^{16}$ municipios y distritos ${ }^{17}$ (funciones establecidas en los artículos 64 y 65 de la Ley 99 de 1993). Los entes territoriales, en principio, aunque hacen parte del Sistema Nacional Ambiental (sI- NA), no comprenden mayores funciones sobre el particular (salvo que se trata de grandes centros urbanos). Por tal razón, en su mayoría los
}

\begin{abstract}
${ }^{16}$ Reza el artículo 64 de la Ley 99 de 1993: "Funciones de los departamentos. Corresponde a los departamentos en materia ambiental, además de las funciones que le sean delegadas por la ley o de las que se le deleguen a los gobernadores por el Ministerio del Medio Ambiente o por las Corporaciones Autónomas Regionales, las siguientes atribuciones especiales: (1) Promover y ejecutar programas y políticas nacionales, regionales y sectoriales en relación con el medio ambiente y los recursos naturales renovables. (2) Expedir, con sujeción a las normas superiores, las disposiciones departamentales especiales relacionadas con el medio ambiente. (3) Dar apoyo presupuestal, técnico, financiero y administrativo a las Corporaciones Autónomas Regionales, a los municipios y a las demás entidades territoriales que se creen en el ámbito departamental, en la ejecución de programas y proyectos y en las tareas necesarias para la conservación del medio ambiente y los recursos naturales renovables. (4) Ejercer, en coordinación con las demás entidades del Sistema Nacional Ambiental (sina) y con sujeción a la distribución legal de competencias, funciones de control y vigilancia del medio ambiente y los recursos naturales renovables, con el fin de velar por el cumplimiento de los deberes del Estado y de los particulares en materia ambiental y de proteger el derecho a un ambiente sano. (5) Desarrollar, con la asesoría o la participación de las Corporaciones Autónomas Regionales, programas de cooperación e integración con los entes territoriales equivalentes y limítrofes del país vecino, dirigidos a fomentar la preservación del medio ambiente común y los recursos naturales renovables binacionales. (6) Promover, cofinanciar o ejecutar, en coordinación con los entes directores y organismos ejecutores del Sistema Nacional de Adecuación de Tierras y con las Corporaciones Autónomas Regionales, obras y proyectos de irrigación, drenaje, recuperación de tierras, defensa contra las inundaciones y regulación de cauces o corrientes de agua, para el adecuado manejo y aprovechamiento de cuencas hidrográficas. (7) Coordinar y dirigir con la asesoría de las Corporaciones Autónomas Regionales, las actividades de control y vigilancia ambientales intermunicipales, que se realicen en el territorio del departamento con el apoyo de la fuerza pública, en relación con la movilización, procesamiento, uso, aprovechamiento y comercialización de los recursos naturales renovables...".
\end{abstract}

${ }^{17}$ Reza el artículo 65 de la Ley 99 de 1993: "Funciones de los municipios, de los distritos y del Distrito Capital de Santafé de Bogotá. Corresponde en materia ambiental a los municipios, y a los distritos con régimen constitucional especial, además de las funciones que le sean delegadas por la ley o de las que se le deleguen o transfieran a los alcaldes por el Ministerio del Medio Ambiente o por las Corporaciones Autónomas Regionales, las siguientes atribuciones especiales: (1) Promover y ejecutar programas y políticas nacionales, regionales y sectoriales en relación con el medio ambiente y los recursos naturales renovables; elaborar los planes programas y proyectos regionales, departamentales y nacionales. (2) Dictar, con sujeción a las disposiciones legales reglamentarias superiores, las normas necesarias para el control, la preservación y la defensa del patrimonio ecológico del municipio. (3) Adoptar los planes, programas y proyectos de desarrollo ambiental y de los recursos naturales renovables, que hayan sido discutidos y aprobados a nivel regional, conforme a las normas de planificación ambiental de que trata la presente ley. (4) Participar en la elaboración de planes, programas y proyectos de desarrollo ambiental y de los recursos naturales renovables a nivel departamental. (5) Colaborar con las Corporaciones Autónomas Regionales, en la elaboración de los planes regionales y en la ejecución de programas, proyectos y tareas necesarios para la conservación del medio ambiente y los recursos naturales renovables. (6) Ejercer, a través del alcalde como primera autoridad de policía con el 
entes territoriales no poseen competencias para otorgar autorizaciones, concesiones, asociaciones, permisos o licencias ambientales, pero sí podrán tomar las medidas que comprende la función a prevención.

Con esto, aunque el sujeto activo de la responsabilidad ambiental en principio, y según Rodríguez, Gómez y Monroy (2012: p. 236), está representado en la Autoridad Nacional de Licencias Ambientales (ANLA), las Corporaciones Autónomas Regionales, las de Desarrollo Sostenible, las Unidades Ambientales de los Grandes Centros Urbanos, los distritos de Cartagena, Santa Marta y Barranquilla, y la Unidad Administrativa Especial del Sistema de Parques Nacionales Naturales, la facultad a prevención puede ser utilizada por entidades que no poseen facultad sancionatoria administrativa ambiental.

La razón seguramente proviene de la necesidad de contar con autoridades que puedan actuar con la inmediatez necesaria para evitar perjuicios o daños a los recursos naturales, aunque desde el punto de vista del derecho administrativo presente dificultades, ya que se está permitiendo que una autoridad (que no posee la competencia) actúe en nombre de otra que sí la tiene, o que usurpe de manera temporal sus funciones. ${ }^{18}$

apoyo de la Policía Nacional y en coordinación con las demás entidades del Sistema Nacional Ambiental (sINA), con sujeción a la distribución legal de competencias, funciones de control y vigilancia del medio ambiente y los recursos naturales renovables, con el fin de velar por el cumplimiento de los deberes del Estado y de los particulares en materia ambiental y de proteger el derecho constitucional a un ambiente sano. (7) Coordinar y dirigir, con la asesoría de las Corporaciones Autónomas Regionales, las actividades de control y vigilancia ambientales que se realicen en el territorio del municipio o distrito con el apoyo de la fuerza pública, en relación con la movilización, procesamiento, uso, aprovechamiento y comercialización de los recursos naturales renovables o con actividades contaminantes y degradantes de las aguas, el aire o el suelo. (8) Dictar, dentro de los límites establecidos por la ley, los reglamentos y las disposiciones superiores, las normas de ordenamiento territorial del municipio y las regulaciones sobre usos del suelo. (9) Ejecutar obras o proyectos de descontaminación de corrientes o depósitos de agua afectados por vertimiento del municipio, así como programas de disposición, eliminación y reciclaje de residuos líquidos y sólidos y de control a las emisiones contaminantes del aire. (10) Promover, cofinanciar o ejecutar, en coordinación con los entes directores y organismos ejecutores del Sistema Nacional de Adecuación de Tierras y con las Corporaciones Autónomas Regionales, obras y proyectos de irrigación, drenaje, recuperación de tierras, defensa contra las inundaciones y regulación de cauces o corrientes de agua, para el adecuado manejo y aprovechamiento de cuencas y microcuencas hidrográficas...”.

${ }^{18}$ Sobre la usurpación de funciones, se debe aclarar que, si la ley contempla la posibilidad de usurpar las funciones, no se trata de un comportamiento por fuera del ordenamiento jurídico. No obstante, se trata de una figura particular y especial que comprende una forma que a la luz de la tradición dogmática del derecho público es conocida como 'usurpación de funciones'. 
Entonces, desde la óptica del derecho administrativo, el elemento órgano no se cumple; por tal razón, si las decisiones producto de la facultad a prevención fuesen examinadas únicamente desde el derecho administrativo, estarían viciadas de nulidad por la correspondiente usurpación de funciones u otras antes citadas. Pero el dinamismo y necesidad de protección de los recursos naturales del derecho ambiental ha generado esta especial figura que avala y permite la Ley 1333.

\subsubsection{Funciones que comprenden la facultad a prevención}

Según la norma objeto de estudio, quienes están facultados para utilizar la facultad a prevención "[...] quedan investidos a prevención de la respectiva autoridad en materia sancionatoria ambiental. En consecuencia, estas autoridades están habilitadas para imponer y ejecutar las medidas preventivas y sancionatorias consagradas en esta ley y que sean aplicables [...]", queriendo con ello establecer efectivamente cuál es su ámbito de competencia o aquello que pueden hacer.

Empero, de la lectura de esta, no es posible abstraer con claridad qué es precisamente aquello con lo cual quedan investidas dichas autoridades. Por lo cual, continuando con el contenido del parágrafo, encontramos que reza: "En todo caso las sanciones solamente podrán ser impuestas por la autoridad ambiental competente para otorgar la respectiva licencia ambiental, permiso, concesión y demás autorizaciones ambientales e instrumentos de manejo y control ambiental, previo agotamiento del procedimiento sancionatorio".

Da a entender la norma que podría el sujeto activo adelantar todo tipo de diligencias en el interior del procedimiento administrativo sancionatorio ambiental, salvo la imposición de las respectivas sanciones.

Con ello, entonces, es posible (aunque los autores no lo comparten) que una autoridad que no posee la competencia funcional para emitir un acto administrativo de carácter sancionatorio administrativo ambiental, de apertura al procedimiento, realice la formulación de los cargos, practique pruebas y otros (claro está, en caso de poder dar cumplimiento al requisito de tiempo que veremos adelante). Esto ya que la norma habla de medidas 'preventivas y sancionatorias' sin determinar qué comprende cada una de ellas. 
No obstante, las decisiones que se tomen en el interior del procedimiento sancionatorio deberían ser emitidas por su competente, so pena de estar viciadas de nulidad, siendo el ius puniendi del Estado netamente reglado.

Aunque, de un breve examen de la realidad, se ha venido reflejando en el comportamiento de las autoridades ambientales que únicamente utilizan la imposición de medidas preventivas con la facultad a prevención. Rueda (2012, p.262) enseña que se trata de que "una autoridad adopta las medidas que resulten necesarias mientras se asegura la actuación de la autoridad a la que en principio le corresponde el ejercicio de las competencias preventivas y sancionatorios que asigna la ley".

\subsubsection{Temporalidad}

El parágrafo del artículo 2 de la Ley 1333 de 2009 plantea que la autoridad que haya tomado la decisión preventiva o sancionatoria deberá dar traslado de las actuaciones a la autoridad ambiental competente dentro de los cinco días hábiles siguientes a la imposición de esta.

Con ello, queriendo limitar el ejercicio de la facultad a prevención. Entonces, a los cinco días de la toma de la decisión o las decisiones necesarias, como se vio en el título anterior, la autoridad que no posee la competencia y que se vio obligada a actuar con el fin de evitar perjuicios al ambiente debe dar traslado a la entidad que por ley posee la función.

Se preguntará el lector qué ocurre si este término es excedido. La consecuencia natural será dar aplicación a la teoría general del acto administrativo, bajo la cual las decisiones por fuera del tiempo establecido en la ley estarán viciadas por ausencia de competencia.

Lo infortunado en la vida práctica es que quien actúa a prevención demora o dilata lo actuado y genera tanto vicios en la toma de decisiones como conflictos de competencia administrativa. Ya han existido diversas situaciones en las cuales la autoridad ambiental que usa la facultad a prevención imponiendo medidas preventivas continúa adelantando el procedimiento sancionatorio excediendo el tiempo y la competencia, obligando así al Ministerio de Ambiente y Desarrollo Sostenible a resolver conflictos administrativos de competencia. Véase como ejemplo de lo anterior el caso ventilado en la Resolución mads 390 del 12 de marzo de 2014. 


\subsubsection{Sin perjuicio de las competencias legales de otras autoridades}

Por último, la norma establece que la utilización de esta figura no disminuye la competencia de otras autoridades, lo cual es perfectamente válido si se trata de competencias no ambientales, como bien podrían ser las penales, fiscales, disciplinarias y otras.

Pero, al no restringirlo la norma, podría también darse el caso en el cual actúan dos entidades del sinA, una a prevención y otra en ejercicio de sus competencias, otorgando al caso un control concurrente, pudiendo violentar principios del debido proceso, como el non bis in idem.

Con todo lo dicho, vimos cómo la figura, aparte de estar diseñada por fuera de la teoría general del acto administrativo, también posee particularidades que la hacen única dentro del ordenamiento jurídico colombiano.

\section{Conclusiones}

Gómez (2012a, p. 263) plantea cómo

podemos afirmar que el derecho ambiental al ser una rama púber del derecho, no respeta y acata en su totalidad las reglas tradicionales de su determinador: el derecho administrativo. Como bien lo enseña Cafferatta (2004,p. 246), citando a Ojeda Mestre, lo anterior ocurre por cuanto el derecho ambiental es novedoso, situación que lo hace especial y diferente a sus congéneres.

Es posible entonces proponer [...] la creación de reglas particulares para el derecho ambiental.

Este sería el caso en el análisis de la facultad a prevención como institución propia y única del derecho sancionatorio ambiental (que no atiende además la tradición dogmática del derecho público), por cuanto:

- Es una figura legal, mediante la cual se permite que una entidad tome temporalmente competencias que la ley no le asigna, sin que por esta razón se presenten vicios en las decisiones adoptadas.

- La pueden utilizar instituciones que no son consideradas autoridades dentro del Sistema Nacional Ambiental.

- Comprende facultades no regladas en el interior del ejercicio del ius puniendi del Estado. 
Lo cual nos lleva indiscutiblemente a concluir que el derecho ambiental, dado su especial, cambiante e imperioso objeto de protección jurídica, ha venido reconociendo en su desarrollo normativo la necesidad de generar una dogmática propia que lo identifique como una rama autónoma de la disciplina jurídica.

\section{Bibliografía}

Berrocal,E.(2001). Manual del acto administrativo. Bogotá: Librería del Profesional. Colombia, Consejo de Estado, Sala de lo Contencioso Administrativo, Sección 4. Sentencia del 30 de abril de 1998. C. P.: Delio Gómez Leyva.

Colombia, Consejo de Estado, Sala de lo Contencioso Administrativo, Sala Plena. Sentencia del 9 de noviembre de 1998. C. P.: Juan Alberto Polo.

Colombia, Consejo de Estado, Sala de lo Contencioso Administrativo, Sección Cuarta. Sentencia del 6 de diciembre de 2012. C. P.: Martha Teresa Briceño de Valencia. Radicación: 25000-23-27-000-2010-00030-01 (18604). Colombia, Consejo de Estado, Sala de lo Contencioso Administrativo, Sección Cuarta. Sentencia del 6 de diciembre de 2012. C. P.: Martha Teresa Briceño de Valencia. Radicación: 25000-23-27-000-2010-00030-01 (18604).

Colombia, Corte Constitucional. Sentencia C-1007 de 2010. M. P.: Humberto Antonio Sierra Porto.

Colombia, Corte Constitucional. Sentencia C-595 de 2010. M. P.: Jorge Iván Palacio Palacio.

Colombia, Corte Constitucional. Sentencia C-742 de 2010.M. P.: Jorge Ignacio Pretelt Chaljub.

Gómez Rey, A. (2012a). La concesión de aguas superficiales en el derecho administrativo. Tendencias del derecho ambiental. Saarbrücken: EAE.

Gómez Rey, A. (2012b). Los actos administrativos inmersos en el procedimiento tendiente a obtener la concesión de aguas superficiales. Una mirada desde la tradición dogmática del derecho público. (Tesis de maestría, Universidad del Rosario, Bogotá, Colombia).

Ossa Arbeláez, J. (2009). Derecho administrativo sancionador. Una aproximación dogmática. Bogotá: Legis.

Páez Páez, I., \& Rodríguez, G. A. (2013). "Las medidas preventivas ambientales, una aproximación desde el derecho administrativo”. Revista Opinión Jurídica, 12(23), 17-30. 
Penagos, G. (2008). El acto administrativo. Tomo I. Parte general, nuevas tendencias. Bogotá: Ed. Doctrina y Ley.

Rodríguez, G. A., Gómez Rey, A., \& Monroy Rosas, J. C. (2012). Las licencias ambientales en Colombia. Una mirada desde la participación y la responsabilidad. Bogotá: Editorial Ibáñez, Universidad del Rosario y Foro Nacional Ambiental.

Rodríguez,L. (2001). Derecho administrativo, general y colombiano. Bogotá:Temis.

Rueda, M. (2012). Ley 1333 de 2009. "Muchos problemas, pocas soluciones”. En G. A. Rodríguez \& I. Páez (Eds.), Temas de derecho ambiental: una mirada desde lo público. Bogotá: Universidad del Rosario.

Santofimio Gamboa, J. O. (1998a). Tratado de derecho administrativo. Tomo I. Bogotá: Universidad Externado de Colombia.

Santofimio Gamboa, J. O. (1998b). Tratado de derecho administrativo. Acto administrativo, procedimiento, eficacia y validez. Tomo II. Bogotá: Universidad Externado de Colombia.

Vidal Perdomo, J. (1994). Derecho administrativo. Bogotá: Temis. 